\title{
Analisis Luas Penampang dan Pengaruh Jarak Terhadap Transmisi Daya pada Wireless Charger Universal Smartphone
}

\author{
Very Bagus Saputra $^{1 *}$, Cahyo Kumolo ${ }^{1}$, Nur Fahmi Fauziati Wibowo ${ }^{1}$ \\ ${ }^{1}$ Jurusan Teknik Elektro \\ Universitas Muhammadiyah Surakarta \\ Surakarta \\ *pheve94@gmail.com
}

\begin{abstract}
Wireless technology is the development of technology that is needed currently given the technological advances in electronic devices very rapidly. Every electronic devices certainly require electric power and cable as the conductor. Therefore, if there is a tool that can transfer electric power without wires, it would be more easy for the user to use the electronic devices. Transfer of electrical energy wireless has several advantages over using a cable that can increase comfort in the use of electrical equipment and can reduce the amount of electronic waste.. The method used for wireless energy transfer in this paperuses an resonance techniques inductive electromagnetic field. User create two shaped copper solenoid coils used to generate the mutual inductance. Wireless electrical energy transfer circuit consists of two circuits that the transmitter and receiver circuit. Transmitter circuit consists of a series LC oscillation andreceiver circuit is a merger several electronic components.

Realization tool works well with setting the appropriate components. However, the effect of distance between the coil greatly affect the value of the electricity that is able to be transferred. The test results showed that the receiver coil sectional area of $2.5 \mathrm{~mm}^{2}$ be able to receive a maximum power of 1.36 watts and the farthest distance of $12 \mathrm{~cm}$. So, the farther away the distance between the coils, the smaller energy capable to be transfer.
\end{abstract}

Key words: wireless technology, transmitter, receiver.

\section{Pendahuluan}

\subsection{Latar Belakang}

Teknologi tanpa kabel yang sering disebut wireless merupakan suatu perkembangan teknologi yang dibutuhkan di era modern sekarang ini.Ketergantungan manusia terhadap perangkat elektronik sangat terasa dikehidupan sehari-hari, dimana semakin banyak perangkat elektronik semakin banyak pula kabel yang dibutuhkan untuk transfer daya.Setiap perangkat ada juga yang digunakan untuk pengisian baterai perangkat elektronik, selain itu juga banyak menarik para peneliti dalam tahun terakhir [1]. Dengan adanya pengembangan teknologi wireless ini daya listrik dapat ditransferkan tanpa menggunakan kabel sebagai perantaranya. Tentunya dengan adanya teknologi wireless ini akan lebih mudah dalam pengisian baterai tanpa ribet dengan kabel.

Alat yang menggunakan kopling magnetik diangaap cocok digunakan pada teknologi ini karena proses pengiriman dayanya tidak menggunakan kontak fisik tetapi menggunakan induksi magnet yang saling berinteraksi [2]. Untuk pentransferan daya listrik ini diperlukan rangkaian transmitter sebagai pemancarnya dan receiver sebagai penerimanya.

Pada abad ke-19 Ilmuwan Nicola Tesla telah mempelajari dan meneliti tentang pemancar dan penerima daya listrik tanpa melalui penghantar atau kabel. Yaitu dengan mengembangkan dan mempelajari sistem induksi elektromagnetik pada kumparan Tesla sampai pada akhirnya Nicola Tesla membangun sebuah menara bernama Wardenclyffe. Menara ini bertujuan untuk pembangkit dan pemancar daya listrik serta pemancar informasi ke seluruh dunia. Yang pada akhirnya menara ini dihancurkan sebelum beroperasi dikarenakan berhentinya sumber dana. Disini bisa dilihat bahwa induksi elektromagnetik juga bisa digunakan untuk transfer daya listrik contohnya trafo yang bisa mengirimkan daya listrik dari lilitan ke lilitan yang lain tanpa menghubungkan kedua lilitan tersebut akan tetapi memerlukan inti besi sebagai tempat berjalannya aliran induksi elektromagnetik serta jarak yang cukup dekat sehingga kurang efisien. Berbeda dengan induksi elektromagnetik pada trafo yang dapat menurun efisiensinya Karena jarak sedangkan resonansi magnetik ini tidak [3]. Sehingga konsep magnetik dapat digunakan untuk mentransfer daya dari lilitan pemancar ke lilitan penerima dengan tegangan tinggi [4].

Dalam penelitian ini, penulis akan membuat rangkaian Prototype Transfer daya listrik tanpa kabel yang terdiri dari rangkaian pemancar dan penerima yang menggunakan prinsip resonansi magnet. Pada rangkaian pemancar berfungsi untuk mengubah energy DC menjadi enegi AC untuk mengirimkan medan magnet melalui frekuensi 
dan kemudian menginduksi lilitan penerima [5]. Untuk mempermudah analisa pada pengujian penulis membuat frekuensi pada pamancar dan penerima dibuat sama dengan besar kapasitor yang sama karena frekuensi dapat mempengaruhi daya yang dipancarkan maupun yang diterima, besar nilainya di ambil dari referensi penelitian sebelumnya [6]. Selain itu penulis juga menganalisa dengan menggunakan besar lilitan yang sama dan berbeda pada rangkaian penerima serta membandingkan jarak yang berbeda-beda pada setiap pasang lilitan untuk menentukan jarak transfer daya listrik yang ideal pada setiap pasang lilitan tersebut. Karena setiap lilitan yang mempunyai panjang, besar penampang dan jumlah lilitan yang berbeda-beda mempunyai optimalisasi sendiri-sendiri [7]. Dengan pengujian ini dapat diketahui dengan masing-masing pasangan lilitan itu berapa daya yang dihasilkan pada jarak ideal tersebut. Sangat di sarankan sistem mempunyai kemampuan yang baik dalam beradaptasi dalam beban yang bervariasi dan mempunyai stabilitas frekuensi yang baik [8].

Teknologi wireless charging pada tahun mendatang dapat dipastikan akan berkembang dengan sangat pesat. Teknologi transmisi daya listrik tanpa kabel ini memiliki banyak kegunaan yang terbagi dalam dua kategori, yaitu memberikan sumber listrik tanpa kabel secara langsung dan mengisi ulang secara otomatis tanpa kabel. Dengan menggunakan teknologi ini, permasalahan/kendala terhadap conventional charger (charger biasa) seminimal mungkin akan dapat dihindari. Untuk itu, teknologi ini sangat layak untuk diimplementasikan.

\subsection{Rumusan Masalah}

Apakah pengaruh jarak terhadap transmisi daya/ energi listrik pada wireless charger universal smartphone?

\subsection{Tujuan Penelitian}

Dapat mengetahui pengaruh jarak terhadap transmisi daya/energi listrik pada wireless charger universal smartphone.

obyek yang lain.

\section{Metode}

Berikut ini tahap-tahap dalam pelaksanaan program yang kami lakukan :

\section{1) Menjalin Kerjasama dengan Mitra}

Menjalin kerjasama dengan bertukar pikiran/gagasan atas persoalan yang ada sehingga dapat ditemukan solusinya dengan langkah berkelanjutan yaitu mitra bersedia untuk memproduksi dengan banyak alat yang sudah berhasil dibuat.

\section{2) Persiapan Alat dan Bahan}

Tahap ini dilakukan dengan proses pencarian dan penelitian alat serta bahan yang dibutuhkan selama proses perakitan dilaksanakan dimulai dari penelitian sampa ipengujian alat yang akan dibuat.

\section{3) Perakitan dan Perancangan}

Tahap ini dilakukan di Laboratorium Fakultas Teknik, Jurusan Teknik Elektro, Universitas Muhammadiyah Surakarta. Metode perancangan alat ini menggunakan prinsip induksi elektromagnetik. Dua hal yang perlu diperhatikan dalam tahap ini adalah komponen transmitter dan receiver sebagai media pengirim dan penerima daya.

\section{a) Transmitter}

Transmitter merupakan rangkaian ascilator yang dapat beresonansi pada frekuensi $2 \mathrm{MHz}$, berikut adalah gambar rangkaian transmitter dimana rangkaian tersebut ditujukan ke sebuah transmitter coil, yaitu lilitan pengirim gelombang elektro magnetik.

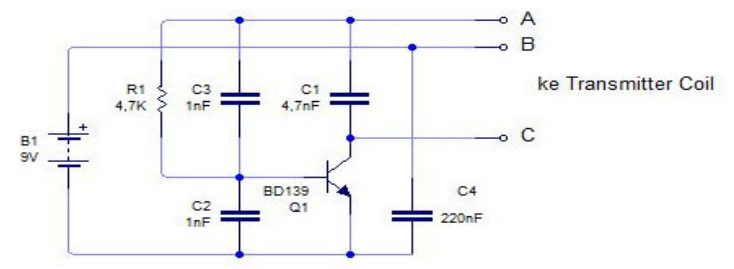

Gambar1. Rangkaian Transmitter

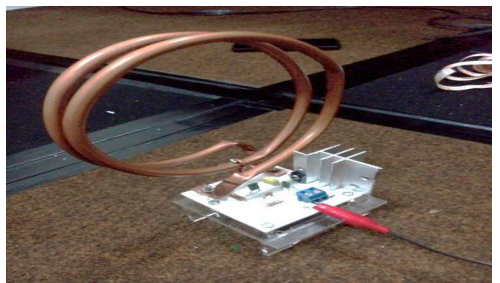

Gambar 2. Komponen Coil Transmitter

\section{b) Receiver}

Receiver berfungsi untuk menerima gelombang elektromagnetik. Penempatan coil dari receiver dan transmitter akan mempengaruhi transfer gelombang elektromagnetik yang dipancarkan, semakin dekat jaraknya maka gelombang yang diterima semakin kuat, maka daya yang diterima akan semakin besar. Hal tersebut juga tergantung dengan diameter coil dan bahan yang digunakan.

ke Receiver Coil

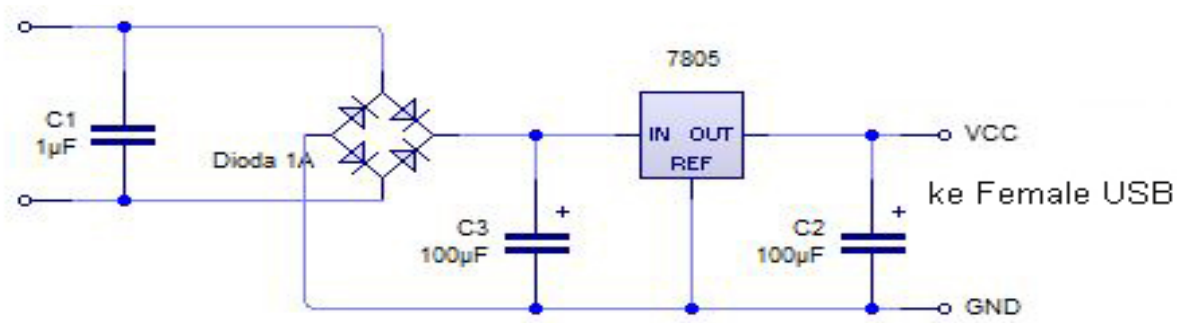

Gambar 3. Rangkaian Receiver 


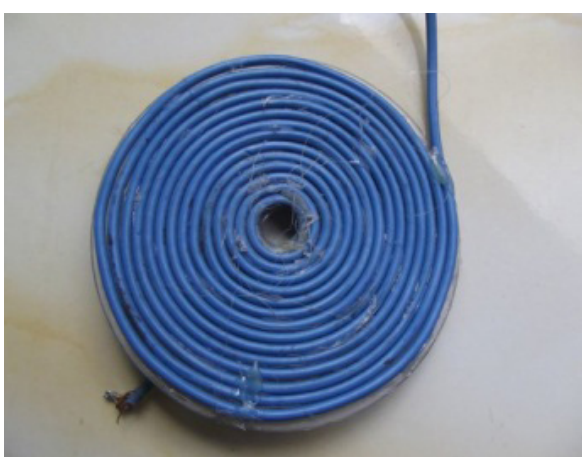

Gambar 4. Komponen Coil Receiver

Selainduakomponen di atas, komponen lain yang pentingdalamperakitanalatiniadalah:
(1) Resistor
(4) Dioda
(2) Kapasitor
(5) Connector USB
(3) Transistor

\section{4) Pengujian Peralatan}

Dalam proses ini dilakukan pengujian kemampuan alat untuk memastikan kualitas dan keandalan dari alat tersebut.

\section{Hasil dan Pembahasan}

\subsection{Perhitungan Frekuensi Resonansi dan Induktansi}

Perhitungan ini digunakan untuk mengetahui berapa induktansi lilitan pada rangkaian pemancar dan masing-masing lilitan pada rangkaian penerima. Kemudian nilai induktansi tersebut digunakan untuk mengetahui berapa frekuensi resonansi pada rangkaian pemancar dan masing-masing rangkaian penerima. Data pada rangkaian lilitan rangkaian pemancar dan penerima adalah sebagai berikut:

Tabel 1. Spesifikasi Rangkaian

\begin{tabular}{ccccccc}
\hline Jenis Rangkaian & $\mathbf{1}(\mathbf{m m})$ & $\mathbf{N}$ & $\mathbf{C}(\mathbf{f a r a d})$ & $\mathbf{A ~ ( \mathbf { m m } ^ { 2 } )}$ & $\begin{array}{c}\mathbf{f r} \\
\text { (Hertz) }\end{array}$ & $\begin{array}{c}\text { L } \\
\text { (Henry) }\end{array}$ \\
\hline Pemancar & 800 & 2 & $1 \times 10^{-9}$ & 28,26 & $?$ & $?$ \\
Penerima 1 & 800 & 2 & $1 \times 10^{-9}$ & 28,26 & $?$ & $?$ \\
Penerima 2 & 2500 & 10 & $1 \times 10^{-9}$ & 1,5 & $?$ & $?$ \\
Penerima 3 & 1800 & 6 & $1 \times 10^{-9}$ & 2,5 & $?$ & $?$ \\
\hline
\end{tabular}

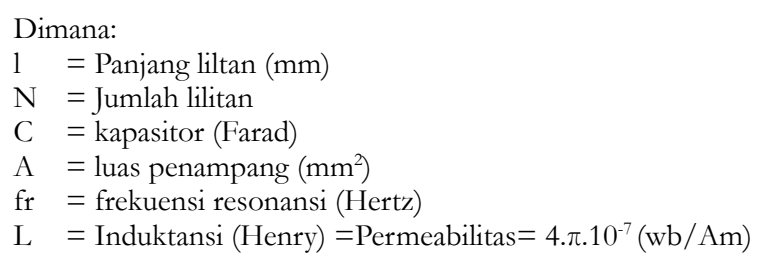

\section{1) Hasil Perhitungan induktansi dan frekuensi} resonansi rangkaian pemancar

Untuk perhitungan induktansi dapat di cari dengan persamaan 5.

Dimana nilai:

$\mathrm{L}=4 \cdot 3,14 \cdot 10^{-7} \cdot \frac{2^{2} \cdot 28,26}{800}$

Sehingga:

$\mathrm{L}=0,17 \mu \mathrm{h}$

Untuk perhitungan frekuensi resonansi dapat di cari dengan persamaan 1 .

Dimana nilai:

$$
\mathrm{fr}=\frac{1}{2.3,14 \cdot \sqrt{0,17 \times 10^{-6} \cdot 1 \times 10^{-9}}}
$$

Sehingga:

$\mathrm{fr}=12 \times 10^{6} \mathrm{~Hz}=12 \mathrm{Mhz}$
2) Hasil Perhitungan induktansi dan frekuensi resonansi rangkaian penerima luas penampang $28,26 \mathrm{~mm}^{2}$.

Untuk perhitungan induktansi dapat di cari dengan persamaan 5.

Dimana nilai:

$\mathrm{L}=4 \cdot 3,14 \cdot 10^{-7} \cdot \frac{2^{2} \cdot 28,26}{800}$

Sehingga:

$\mathrm{L}=0,17 \mu \mathrm{h}$

Untuk perhitungan frekuensi resonansi dapat di cari dengan persamaan 1 .

Dimana nilai:

$\mathrm{fr}=\frac{1}{2.3,14 \cdot \sqrt{0,17 \times 10^{-6} \cdot 1 \times 10^{-9}}}$

Sehingga:

$\mathrm{fr}=12 \times 10^{6} \mathrm{~Hz}=12 \mathrm{Mhz}$ 
3) Hasil Perhitungan induktansi dan frekuensi resonansi rangkaian penerima luas penampang $1,5 \mathrm{~mm}^{2}$

Untuk induktansi ini dapat dicari dengan persamaan 5 .

Dimana nilai:

$L=4 \cdot 3,14 \cdot 10^{-7} \cdot \frac{10^{2} \cdot 1,5}{2500}$

\section{Sehingga:}

$\mathrm{L}=0,075 \mu \mathrm{h}$

Untuk frekuensi resonansi ini dapat dicari dengan persamaan 1.

Dimana nilai:

$$
\mathrm{fr}=\frac{1}{2.3,14 \cdot \sqrt{0,075 \times 10^{-6} \cdot 1 \times 10^{-9}}}
$$

\section{Sehingga:}

$\mathrm{fr}=18 \times 10^{6}=18 \mathrm{Mhz}$

\section{4) Hasil Perhitungan induktansi dan frekuensi} resonansi rangkaian penerima luas penampang $2,5 \mathrm{~mm}^{2}$

Untuk induktansi ini dapat dicari dengan persamaan 5.

Dimana nilai:

$$
L=4 \cdot 3,14 \cdot 10^{-7} \cdot \frac{6^{2} \cdot 2,5}{1800}
$$

Untuk frekuensi resonansi ini dapat dicari dengan persamaan 1.

Dimana nilai:

$\mathrm{fr}=\frac{1}{2.3,14 \cdot \sqrt{0,062 \times 10^{-6} \cdot 1 \times 10^{-9}}}$

Sehingga:

$\mathrm{fr}=20 \times 10^{6}=20 \mathrm{Mhz}$

\subsection{Pengujian dengan Lilitan Penerima Luas} Penampang 28,26 $\mathrm{mm}^{2}$

Pengujian ini dilakukan dengan lilitan pemancar yang mempunyai nilai frekuensi resonansi $12 \mathrm{Mhz}$ dengan lilitan penerima yang sama seperti lilitan pemancar dengan nilai frekuensi resonansi 12Mhz. Nilai arus dan tegangan dari hasil pengujian adalah sebagai berikut, dan nilai daya didapat dari persamaan sedangkan nilai efisiensi didapat dari persamaan $\mathrm{Eff}=\frac{\text { daya penerima }}{\text { daya pemancar }} \cdot 100 \%$

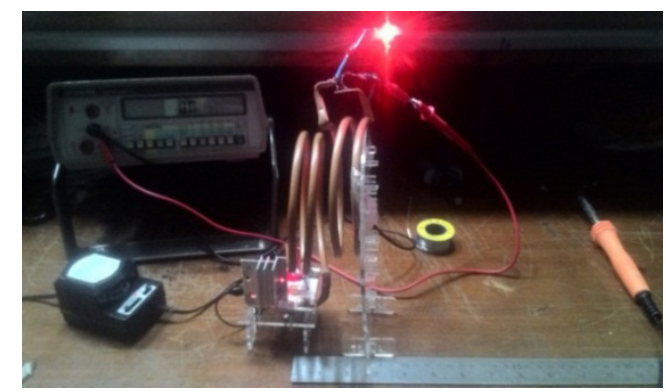

Gambar 5. Pengujian Lilitan Penerima Luas Penampang $28,26 \mathrm{~mm}^{2}$

Sehingga:

$\mathrm{L}=0,062 \mu \mathrm{h}$

Tabel 2. Hasil Pengujian Lilitan Penerima Luas Penampang 28,26 $\mathrm{mm}^{2}$

\begin{tabular}{cccccccc}
\hline \multirow{2}{*}{$\begin{array}{c}\text { Jarak } \\
(\mathbf{c m})\end{array}$} & $\begin{array}{c}\text { Tegangan } \\
\text { (V) }\end{array}$ & Arus (A) & $\begin{array}{c}\text { Daya } \\
\text { (Watt) }\end{array}$ & $\begin{array}{c}\text { Tegangan } \\
\text { (V) }\end{array}$ & $\begin{array}{c}\text { Arus } \\
(\mathbf{A})\end{array}$ & $\begin{array}{c}\text { Daya } \\
\text { (Watt) }\end{array}$ & $\begin{array}{c}\text { Efisiensi } \\
\mathbf{( \% )}\end{array}$ \\
\hline 2 & 13,5 & 0,18 & 2,43 & 6,4 & 0,05 & 0,32 & 13,16 \\
4 & 13,5 & 0,18 & 2,43 & 5,2 & 0,04 & 0,20 & 8,23 \\
6 & 13,5 & 0,18 & 2,43 & 4,1 & 0,02 & 0,08 & 3,29 \\
8 & 13,5 & 0,18 & 2,43 & 3,1 & 0,01 & 0,03 & 1,23 \\
10 & 13,5 & 0,18 & 2,43 & 2,2 & 0 & 0 & 0 \\
12 & 13,5 & 0,18 & 2,43 & 1,8 & 0 & 0 & 0 \\
14 & 13,5 & 0,18 & 2,43 & 1,2 & 0 & 0 & 0 \\
16 & 13,5 & 0,18 & 2,43 & 0,9 & 0 & 0 & 0 \\
18 & 13,5 & 0,18 & 2,43 & 0,8 & 0 & 0 & 0 \\
20 & 13,5 & 0,18 & 2,43 & 0,6 & 0 & 0 & 0 \\
\hline
\end{tabular}

\subsection{Pengujian dengan Lilitan Penerima Luas}

Penampang $1,5 \mathrm{~mm}^{2}$

Pengujian ini dilakukan dengan lilitan pemancar yang mempunyai nilai frekuensi resonansi $12 \mathrm{Mhz}$ dengan lilitan penerima dengan nilai frekuensi resonansi $18 \mathrm{Mhz}$.
Nilai arus dan tegangan dari hasil pengujian adalah sebagai berikut, dan nilai daya didapat dari persamaan sedangkan nilai efisiensi didapat dari persamaan $\mathrm{Eff}=\frac{\text { daya penerima }}{\text { daya pemancar }} \cdot 100 \%$ 


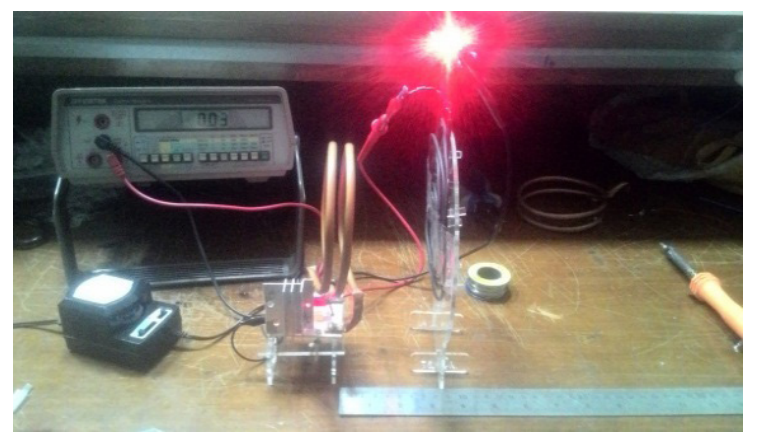

Gambar 6. Pengujian Lilitan Penerima Luas Penampang $1,5 \mathrm{~mm}^{2}$

Tabel 3. Hasil Pengujian Lilitan Penerima Luas Penampang 1,5 mm²

\begin{tabular}{|c|c|c|c|c|c|c|c|}
\hline \multirow{2}{*}{$\begin{array}{l}\text { Jarak } \\
(\mathrm{cm})\end{array}$} & \multicolumn{3}{|c|}{ Pemancar } & \multicolumn{3}{|c|}{ Penerima } & \multirow{2}{*}{$\begin{array}{c}\text { Efisiens } \\
(\%)\end{array}$} \\
\hline & $\begin{array}{l}\text { Tegangan } \\
\text { (V) }\end{array}$ & Arus (A) & $\begin{array}{l}\text { Daya } \\
\text { (Watt) }\end{array}$ & $\begin{array}{c}\text { Tegangan } \\
\text { (V) }\end{array}$ & $\begin{array}{l}\text { Arus } \\
\text { (A) }\end{array}$ & $\begin{array}{c}\text { Daya } \\
\text { (Watt) }\end{array}$ & \\
\hline 2 & 13,5 & 0,18 & 2,43 & 11,2 & 0,06 & 0,67 & 27,57 \\
\hline 4 & 13,5 & 0,18 & 2,43 & 10,5 & 0,05 & 0,52 & 21,39 \\
\hline 6 & 13,5 & 0,18 & 2,43 & 8,8 & 0,04 & 0,35 & 14,40 \\
\hline 8 & 13,5 & 0,18 & 2,43 & 6,9 & 0,03 & 0,20 & 8,23 \\
\hline 10 & 13,5 & 0,18 & 2,43 & 4,3 & 0,02 & 0,08 & 3,29 \\
\hline 12 & 13,5 & 0,18 & 2,43 & 2,4 & 0,01 & 0,02 & 0,82 \\
\hline 14 & 13,5 & 0,18 & 2,43 & 1,5 & 0 & 0 & 0 \\
\hline 16 & 13,5 & 0,18 & 2,43 & 1,0 & 0 & 0 & 0 \\
\hline 18 & 13,5 & 0,18 & 2,43 & 0,8 & 0 & 0 & 0 \\
\hline 20 & 13,5 & 0,18 & 2,43 & 0,6 & 0 & 0 & 0 \\
\hline
\end{tabular}

\subsection{Pengujian dengan Lilitan Penerima Luas}

\section{Penampang 2,5 $\mathrm{mm}^{2}$}

Pengujian ini dilakukan dengan lilitan pemancar yang mempunyai nilai frekuensi resonansi $12 \mathrm{Mhz}$ dengan lilitan penerima dengan nilai frekuensi resonansi 20Mhz. Nilai arus dan tegangan dari hasil pengujian adalah sebagai berikut, dan nilai daya didapat dari persamaan sedangkan nilai efisiensi didapat dari persamaan $\mathrm{Eff}=\frac{\text { daya penerima }}{\text { daya pemancar }} \cdot 100 \%$

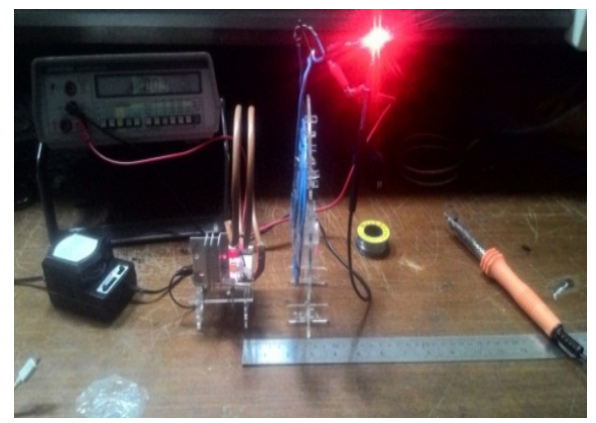

Gambar 7. Pengujian Lilitan Penerima Luas Penampang 2,5 $\mathrm{mm}^{2}$

Tabel 4. Hasil Pengujian Lilitan Penerima Luas Penampang $2,5 \mathrm{~mm}^{2}$

\begin{tabular}{cccccccc}
\hline \multirow{2}{*}{$\begin{array}{c}\text { Jarak } \\
(\mathbf{c m})\end{array}$} & $\begin{array}{c}\text { Tegangan } \\
\text { (V) }\end{array}$ & Arus (A) & $\begin{array}{c}\text { Daya } \\
\text { (Watt) }\end{array}$ & $\begin{array}{c}\text { Tegangan } \\
\text { (V) }\end{array}$ & $\begin{array}{c}\text { Arus } \\
\text { (A) }\end{array}$ & $\begin{array}{c}\text { Daya } \\
\text { (Watt) }\end{array}$ & $\begin{array}{c}\text { Efisiensi } \\
(\mathbf{\%})\end{array}$ \\
\hline 2 & 13,5 & 0,18 & 2,43 & 22,8 & 0,06 & 1,36 & 55,96 \\
4 & 13,5 & 0,18 & 2,43 & 21,0 & 0,05 & 1,05 & 43,20 \\
6 & 13,5 & 0,18 & 2,43 & 18,7 & 0,04 & 0,74 & 30,45 \\
8 & 13,5 & 0,18 & 2,43 & 15,0 & 0,03 & 0,45 & 18,51 \\
10 & 13,5 & 0,18 & 2,43 & 11,2 & 0,02 & 0,22 & 9,05 \\
12 & 13,5 & 0,18 & 2,43 & 8,0 & 0,01 & 0,08 & 3,29 \\
14 & 13,5 & 0,18 & 2,43 & 6,6 & 0 & 0 & 0 \\
16 & 13,5 & 0,18 & 2,43 & 4,2 & 0 & 0 & 0 \\
18 & 13,5 & 0,18 & 2,43 & 3,1 & 0 & 0 & 0 \\
20 & 13,5 & 0,18 & 2,43 & 2,2 & 0 & 0 & 0 \\
\hline
\end{tabular}




\section{Diskusi}

Setelah melakukan pengujian dengan merubah liltan pada rangkaian penerima yang mempunyai nilai induktansi dan frekuensi resonansi yang sama dan berbeda-beda dengan lilitan pemancar dengan jarak yang berbedabeda, maka perbandingan hasil daya dan efisiensi yang didapatkan dari masing-masing lilitan adalah sebagai berikut.

Tabel 5. Hasil Perbandingan Seluruh Pengujian

\begin{tabular}{|c|c|c|c|c|c|c|c|}
\hline \multirow{2}{*}{$\begin{array}{l}\text { Jarak } \\
(\mathrm{cm})\end{array}$} & \multirow{2}{*}{$\begin{array}{c}\text { Daya } \\
\text { Pemancar } \\
\text { (W) }\end{array}$} & \multicolumn{2}{|c|}{$\begin{array}{l}\text { Penerima } \\
28,26 \mathrm{~mm}^{2}\end{array}$} & \multicolumn{2}{|c|}{$\begin{array}{c}\text { Penerima } \\
1,5 \mathrm{~mm}^{2}\end{array}$} & \multicolumn{2}{|c|}{$\begin{array}{c}\text { Penerima } \\
2,5 \mathrm{~mm}^{2}\end{array}$} \\
\hline & & $\mathbf{P}(\mathrm{W})$ & Eff(\%) & $\mathbf{P}(\mathrm{W})$ & Eff $(\%)$ & $P(W)$ & Eff(\%) \\
\hline 2 & \multirow{10}{*}{2,43} & 0,32 & 13,16 & 0,67 & 27,57 & 1,36 & 55,96 \\
\hline 4 & & 0,20 & 8,23 & 0,52 & 21,39 & 1,05 & 43,20 \\
\hline 6 & & 0,08 & 3,29 & 0,35 & 14,40 & 0,74 & 30,45 \\
\hline 8 & & 0,03 & 1,23 & 0,20 & 8,23 & 0,45 & 18,51 \\
\hline 10 & & 0 & 0 & 0,08 & 3,29 & 0,22 & 9,05 \\
\hline 12 & & 0 & 0 & 0,02 & 0,82 & 0,08 & 3,29 \\
\hline 14 & & 0 & 0 & 0 & 0 & 0 & 0 \\
\hline 16 & & 0 & 0 & 0 & 0 & 0 & 0 \\
\hline 18 & & 0 & 0 & 0 & 0 & 0 & 0 \\
\hline 20 & & 0 & 0 & 0 & 0 & 0 & 0 \\
\hline
\end{tabular}

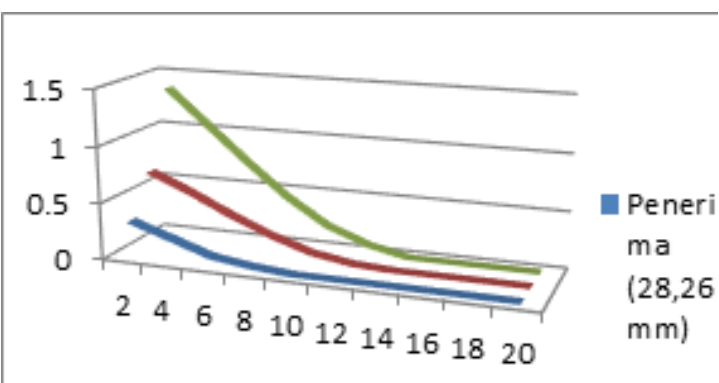

Gambar 8. Grafik Hubungan Jarak Dengan Daya

Dari grafik yang ditunjukan pada gambar 9 menunjukkan bahwa semakin dekat jarak lilitan pemancar dengan lilitan penerima maka semakin besar daya yang dihasilkan, pada jarak $2 \mathrm{~cm}$ lilitan dengan luas penampang 2,5 mm2 mampu menerima daya dua kali lebih besar dari lilitan dengan luas penampang $1,5 \mathrm{~mm} 2$ dan empat kali lebih besar dari lilitan dengan luas penampang 28,26 $\mathrm{mm} 2$. Untuk efektifitas lilitan dengan luas penampang 28,26 mm2 hanya mampu menerima daya listrik sampai dengan jarak $8 \mathrm{~cm}$, sedangkan lilitan penerima dengan luas penampang 1,5 dan $2,5 \mathrm{~mm} 2$ mampu menerima daya hingga jarak $12 \mathrm{~cm}$.

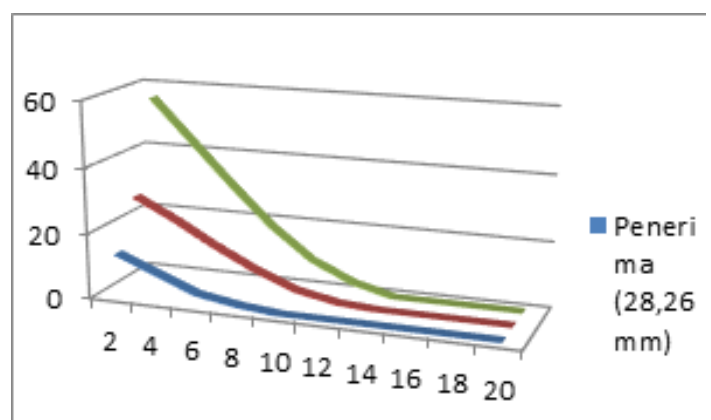

Gambar 9. Grafik Hubungan Jarak Dengan Efisiensi
Dari grafik yang ditunjukan pada gambar 10 menunjukkan bahwa jarak yang paling dekat yaitu 2 $\mathrm{cm}$ mempunyai tingkat efisiensi yang paling baik dalam menerima daya listrik, lilitan penerima dengan luas penampang $2,5 \mathrm{~mm}^{2}$ mempunyai efisiensi paling baik hingga $55,95 \%$ pada jarak $2 \mathrm{~cm}$. Pada jarak paling jauh dalam menerima daya listrik yaitu $12 \mathrm{~cm}$ lilitan penerima dengan luas penampang $1,5 \mathrm{~mm}^{2}$ mempunyai efisiensi $0,82 \%$ sedangkan lilitan penerima dengan luas penampang 2,5 $\mathrm{mm}^{2}$ masih mempunyai efisiensi sebesar 3,29\% berbeda dengan lilitan dengan luas penampang 28,26 $\mathrm{mm}^{2}$ yang hanya mempunyai efisiensi $1,23 \%$ pada jarak maksimal $8 \mathrm{~cm}$.

\section{Kesimpulan}

Berdasarkan hasil pengujian rangkaian wireless charger universal smartphone dengan mengganti nilai jarak antara transmitter dan receiver dapat ditarik kesimpulan bahwa lilitan penerima yang sama seperti lilitan pemancar dalam bentuk, luas penampang maupun nilai frekuensi resonansinya tidak menjamin bisa maksimal dalam menerima daya listrik bahkan hanya mampu menerima daya listrik pada jarak $8 \mathrm{~cm}$.

Dari seluruh pengujian lilitan penerima yang paling baik menerima daya listrik yaitu lilitan dengan luas penampang $2,5 \mathrm{~mm}^{2}$ yang dapat menerima daya listrik hingga jarak $12 \mathrm{~cm}$ dengan daya maksimal 1,36 watt dengan efisiensi sebesar 55,96\%.

Jarak terjauh dalam pengujian ini yaitu $20 \mathrm{~cm}$ dengan tegangan pemancar sebesar 13,5 volt lilitan penerima dengan luas penampang $2,5 \mathrm{~mm}^{2}$ masih mampu menerima tegangan sebesar 2,2 volt pada jarak tersebut.

\section{Persantunan}

Penulis mengucapkan terimakasih kepada pihak -pihak yang telah meluangkan waktu membantu proses penelitian ini: Kemenristekdikti yang telah mendanai 
penelitian ini dalam skim PKM dan Bapak Hasyim Asy'ari, ST.,MT. selaku pembimbing.

\section{Daftar Pustaka}

[1] W. Hu, H. Zhou, Q. Deng, \& X. Gao, “Optimization algorithm and practical implementation for 2-coil wireless power transfer systems." In American Control Conference (ACC) 2014, pp. 4330-4335. IEEE, 2014.

[2] M. Muchtar, "Terobosan Baru Transmisi Energi Listrik Tanpa Kabel," dalam PROSIDING CSGTEIS 2013, 2013

[3] L. Zhao, \& Y. Liu, Simulation of Magnetic Resonance for Wireless Power, 2013.

[4] J. Agbinya, Wireless Power Transfer, River Publishers, 2012.
[5] K.S. Lwin, \& H.M. Tun, "Design And Construction Of Wireless Charging System Using Inductive Coupling," International Journal of Technology Enhancements and Emerging Engineering Research 4(06), 282-287, 2015.

[6] I.M.B. Suksmadana, RANCANG BANGUN SISTEM TRANSFER DAYA LISTRIK NIRKABEL.

[7] P.A. Pynanjung, B.P. Lapanporo, I.D. Faryuni. "Optimasi Rangkaian dan Material Kumparan pada Rangkaian Transfer Listrik Tanpa Kabel Terhadap Jarak Jangkauan Pengiriman Energi Listrik," PRISMA FISIKA II(2), 2014.

[8] Y. Guo, C. Zhu, R. Lu, G. Wei, \& K. Song, "Resonant enhanced parallel-T topology for weak coupling wireless power transfer pickup applications," The Journal of Engineering, pp. 2014-2016, http://doi. org/10.1049/joe.2014.0343, 2015. 